\title{
Empirical Research on New Stock IPO Excess Returns of the Shadow Shares Behind
}

\author{
Huang Yu Cheng, Zhang Fei \\ Organization School of Economics, Shanghai University, Shanghai City, China
}

Email address:

nightwis@163.com (Huang Yu Cheng),zf528@126.com (Zhang Fei)

\section{To cite this article:}

Huang Yu Cheng, Zhang Fei. Empirical Research on New Stock IPO Excess Returns of the Shadow Shares Behind. International Journal of Economics, Finance and Management Sciences. Vol. 4, No. 6, 2016, pp. 331-336. doi: 10.11648/j.ijefm.20160406.13

Received: September 26, 2016; Accepted: October 31, 2016; Published: November 3, 2016

\begin{abstract}
In China's securities market, "shadow share" is the phenomenon of frequent speculation. Based on the present situation, this paper makes systematic empirical research and tracking on the excess return of "shadow share", And explores the underlying causes of excess returns. Basically, by selecting 89 samples of different plate and market environment, this article studies the cumulative abnormal return (CAR) and abnormal average return (AR) of "shadow share", And draw the following conclusions: In main board and GEM market, the cumulative abnormal return (CAR) of "shadow share" is positive, however, in small and medium board, it becomes negative; In choppy market and rapid declining market, the cumulative abnormal return (CAR) of "shadow share" is positive, while it becomes negative in accelerate rising market.
\end{abstract}

Keywords: Shadow Share, IPO, Cumulative Abnormal Return

\section{Introduction}

In China's securities market, the "shadow share" speculation is a common phenomenon. The so-called "shadow share" refers to a listed company industry which is similar to another prepared listed company's industry, then the listed company will be known as the "shadow shares." After the Initial Public Offerings (IPO), the stock will usually speculate to rise, so the "shadow share" is also the first to speculate. In the generally rising market, this phenomenon is commonplace. For example, in May of last year, after Guotai Junane's disclosing prospectus, on the next day its "shadow shares" have a collective surge. Among them, Shenzhen Energy (direct equity $2.53 \%$ ), Public Transportation (direct equity $2.53 \%$ ), Jin Jiang Investment (direct equity 1.2\%), Daleng Shares (direct equity $0.6 \%$ ) collective increase limits; Guangda Securities rose 5.41\%, Furi Electronics rose $4.08 \%$, Luzhou Laojiao rose 3.26\%, and Jiaoda Li'ang rose 2.93\%. At present, research on this phenomenon is only confined to simple narrative and deeper cause is also simply attributes to market's habit, but such research and interpretation are too superficial and unconvincing. For the first time, this paper expands systematic empirical research and tracking on the excess returns of "shadow share", and then discusses deeper causes of excess returns.
The research of China's scholars are currently focused on VC (venture capital) concept stocks that is similar to "shadow share", venture capital stocks are also essentially shadow shares. The so-called venture capital stock refers to shares of listed companies that is involved in venture capital risk, and is expected to gain in the IPO, or has concept of "spin-off" listing. Basic research has two directions, the first is discuss price fluctuations of venture capital stocks itself. Huang Guoxuan (2009) studied the price fluctuations of venture capital stocks, and he thinks that investors' invested behavior and psychology have an important impact on the stock price, at the same time, he concerns about the monetary policy and price volatility of venture capital stock [1]. Shasha, Wang Jiheng (2008) uses venture capital of listed companies as the research object, and $\mathrm{P} / \mathrm{B}$ ratio and net assets yield ratio as the standard, and divides into 13 industries to explore the correlation between listed companies' changes in performance and stock price changes [2]. The second is to explore the impact on venture capital to the stock price of equity shares. Wang Weijie (2010) studied the underpricing case of IPO shares that listed on the venture capital firm, and he believes that when investors invest in companies that venture capital institutions participating, then they exhibit 
higher irrational level, and longer duration, thus further pushing up the underpricing rate of such enterprises IPO [3]. Ye Xingde (2013) based on the perspective of whether or not the participation of venture capital, did comparative analysis of whether venture capital institutions affect IPO market performance on the first day [4]. Sun Min (2010) found that VC-backed company IPO's operating performance three years ago significantly worse than non-VC-backed companies, but the gap with non-venture company reduced year after year [5]. Chen Wei (2014) analyzed listed companies liquidity by using venture capital reducing holdings data in SMEs board and GEM, and he found the greater number of venture capital reducing holdings makes the higher stock liquidity [6].

\section{Theoretical Analysis of the Impact}

The nature of the stock is a commodity, so stock in line with demand and supply economics theory. When investors find a stock is undervalued, and the prices is expected to rise, then investors will be the first to buy the stock, causing the demand is greater than supply in stock market, so stock prices will rise. On the contrary, if the stock is overvalued and price expected to fall, investors will be the first to sell, causing supply exceeds demand in the market, the result is that the share price pullback. So, if investors want to get excess returns, they must master accurate opportunity in transactions, that is to say faster than ordinary market participants-- buy the stock before investors generally buying shares and the stock price rising, and sell before investors generally selling shares and the stock price descending.

In China's securities market, the IPO will generally have the daily limit for several days, and as the company holds a minority proportion of such shares as long-term equity investment, the impact of changes in the portion of fair value this year's investment income will increase each stock's net gains, and then because of $\mathrm{P}=\mathrm{EPS} * \mathrm{PE}$, and in the $\mathrm{PE}$ unchanged conditions, EPS increases will promote $\mathrm{P}$ rises, so in the semi-strong form efficient market, the market will quickly discover this opportunity, and this "shadow shares "is bound to be concerned about capital.

Firstly, taking into account the expected effect, during the formal disclosure of the prospectus and the IPO trading, pioneer will give priority to layout such "shadow share", so the price of "shadow share" will give a reaction before the IPO transaction, and its performance has excess return. Secondly, with the advent of IPO of new shares trading day, the market expects investors will chase new shares, while both fit expectation, there will be the results of each game, so the IPO first traded day and even a few days ago there must be a pioneer reacts in advance, and reduces such shares early, as a result, the excess return of such shares may be negative. Finally, the IPO officially trade in the market, and funds prefer to "authentic" shares, then the "shadow share" may be sell by the slowest investors, and the rate of excess return should be negative or not significant.

\section{An Empirical Analysis on the Influence}

\subsection{Research Methods Introduction}

According to the process of initial listed Company in main board market, this paper uses event study method and considers trading day of IPO as the event date, and then inspects excess return in two time periods that from new shares' prospectus date to offering date and after offering date. The former period is four weeks or only two weeks, so we have chosen three weeks (15 trading days) for the window period $[-15,0]$. Firstly, window period of the latter should not be too long, because long window period may result in complex market factors other than new shares trading factor, it also does not reflect the "shadow stock" real market performance. Secondly, choosing window period should not be too short in case "shadow stock" has no enough time to digest the impact of new shares trading in the market, share price could fully adjusted in place. After comprehensive considering, we select 15 days (after the IPO transaction) as a window period to research.

Firstly, we estimate the whole relevance between single "shadow stock" and market in the estimated period of event, in order to calculate a single stock expected rate of return, seen equation (1). It should be noted that the day before $\alpha$ and $\beta$ are estimated starts on March 1, 2013, the termination date is the day before the window period, namely -16 days. Secondly, we calculate the excess returns separately in two period that is the window before event $[-15,0]$ and the window behind event $[0$, $15]$, seen equation (2). Finally, we calculate the accumulated abnormal average excess return of this stocks CAR (Cumulative Abnormal Return), seen equation (3).

$$
\begin{array}{r}
R_{\mathrm{it}}=\alpha_{\mathrm{i}}+\beta_{\mathrm{i}} R_{m t}+\varepsilon_{i t} \rightarrow E\left(R_{\mathrm{it}}\right)=\alpha_{\mathrm{i}}+\beta_{\mathrm{i}} R_{m t} \\
A R_{i t}=R_{i t}-E\left(R_{i t}\right) \\
C A R\left(t_{1}, t_{2}\right)=\frac{1}{N} \sum_{t_{1}}^{t_{2}} \sum_{i=1}^{N} A R_{\mathrm{it}}
\end{array}
$$

\subsection{Research Methods and Sample Selection}

"Shadow stock" can be divided into three categories: The first category is the direct holdings of listed companies; the second is a listed company related parties, both of which belong to the same controlling shareholder; the third category is the more common type of venture. Therefore, this paper is based on the first and third categories to find relevant types of samples, specifically IPO "shadow stock" listed on January 1, 2013 to May 1, 2016, for example: Shenjing shares begun IPO on December 31, 2015, listed company Huihong Group (600981) direct equity participation 6.4\%, Huachang Chemical (002274) direct shareholding 3.83\%, So Huihong Group and Huachang Chemical is the "shadow shares." Another example is: GuangXin Shares begun IPO on May 13, 2015, and listed company Nantian Information (000948) indirectly holds $3.13 \%$ shares by Anhui Guo'an Investment Co., Ltd., it is also consistent with the 
information we require sample. It must be noted that we excluded the Hong Kong "shadow stock" and some obscure samples behind "shadow stock", because these companies may well cross-shareholdings, internal specific ownership structure that is difficult to clear, then the final number of samples to meet the requirements is 39 . These sample data related to financial information terminal part from the Wind database.

\subsection{The Empirical Result Analysis}

\subsubsection{The Total Sample Analysis Results}

On the back of the main board and gem listing new shares, shadow share" accumulated excess yield characteristics are similar. The both CAR $[-8,0]$ are obvious positive, and reach $3.6 \%$ and $2.96 \%$, respectively. This illustrates "shadow shares" of main board and gem are more popular with the market, and capital market continues to hype such stocks, the excess yields and CAR [0,7] fluctuate small after the new shares traded, so even new stocks to be listed, there is less impact on "shadow share", and the excess yields are not significant, as a whole it has been relatively strong performance. However, on the back of the SMEs board listing new shares, performance of "shadow shares" is thoughtful: the market for this kind of "shadow shares" continues bearishly, specifically the CAR $[-14,0]$ is $-2.87 \%$, CAR $[0,7]$ is $2.3 \%$. After the new share's prospectus disclosure, investors respond quickly to watch and even decrease stock holdings. On the IPO trading day, the money towards "authentic" new shares, the market began to clear the stock sell-off, then the excess yields is negative. However, it is also possible that the huge capital covers delivery using good news that new shares traded on the "one word board".
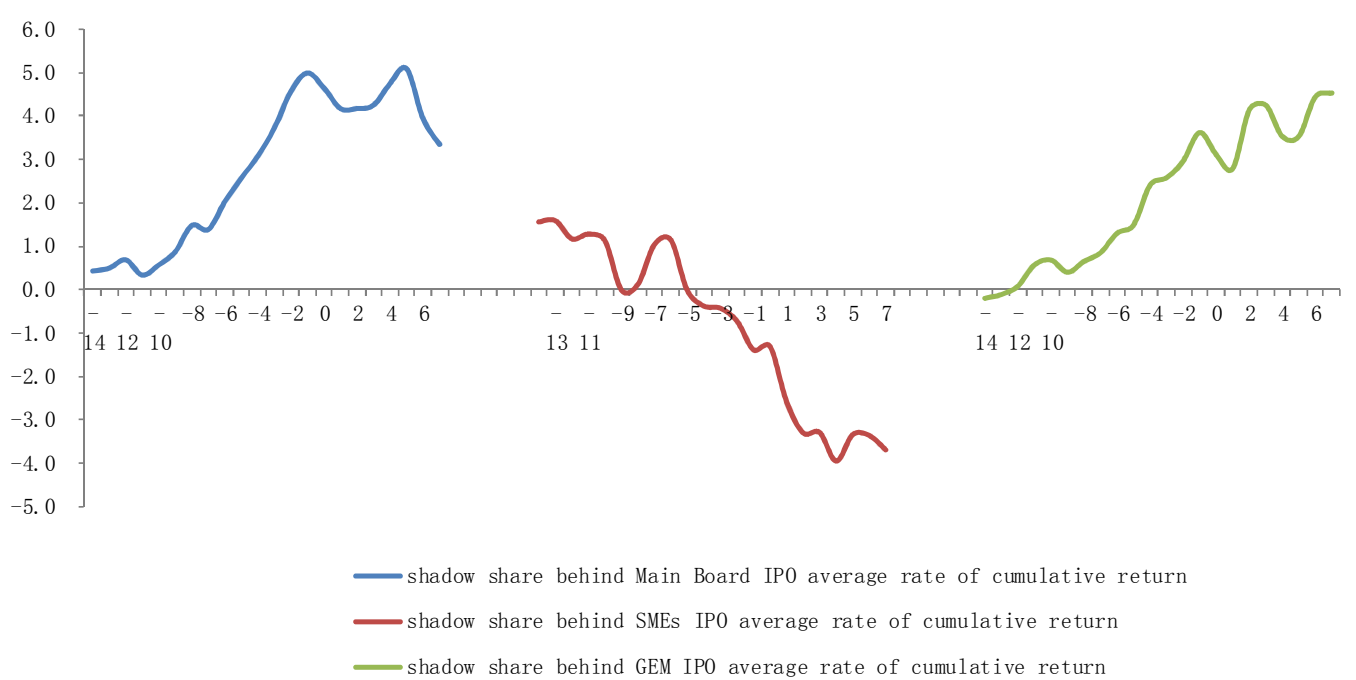

Figure 1. Shadow share behind different IPO average rate of cumulative return.

Eight days before Main Board and GEM IPO excess returns are significantly positive, probably because the huge capital has strong control on related stocks, and squeezes down the share price continuously in the $[-14,-9]$ period to learn more chips, then raises the price or releases forecast information of upbeat earnings to get the market concern, also creating opportunity while reducing the shares behind, in order to obtain excess returns. After the IPO transaction, the two plates "shadow share" growth trend of excess returns are over, indicating that the market respond to the information of shares transaction, investors expect the hot speculation temporarily ended, taking into account the additional information on the market, weakening the enthusiasm of "shadow share", waiting or reducing shares, then the capital is not flowing into the stock, and excess yields are not significant continuously.

For SMEs, after IPO transaction, the down trend of cumulative return is more pronounced, indicating that the market respond more violent to shares trade, and investors game each other, and are expected counterpart will be decreased. Thus investors reduce actively, and funds outflow continuously, and the excess return is significantly negative.

Table 1. Cumulative return of "shadow share" significant Statistics - Main board.

\begin{tabular}{lll}
\hline $\mathbf{t}$ & CAR $[-\mathbf{1 5}, \mathbf{t}] \mathbf{~ ( \% )}$ & T Ratio \\
\hline-8 & $1.50^{* *}$ & 2.11 \\
-7 & $1.41^{* *}$ & 1.92 \\
-6 & 2.06 & 2.17 \\
-5 & $2.62^{* *}$ & 2.32 \\
-4 & 3.13 & 2.41 \\
-3 & $3.79^{* *}$ & 2.53 \\
-2 & $4.66^{* * *}$ & 2.82 \\
-1 & $5.09^{* * *}$ & 2.78 \\
0 & $4.73^{* * *}$ & 2.57 \\
1 & $4.24^{* * *}$ & 2.41 \\
2 & $4.24^{* * *}$ & 2.41 \\
3 & $4.32^{* * *}$ & 2.3 \\
4 & $4.83^{* * *}$ & 2.35 \\
5 & $5.17^{* * *}$ & 2.33 \\
6 & $3.99^{* * *}$ & 2.08 \\
7 & $3.38^{* * *}$ & 1.91 \\
\hline
\end{tabular}


Table 2. Cumulative return of "shadow share" significant Statistics - SME.

\begin{tabular}{lll}
\hline $\mathbf{t}$ & CAR [-15, t] $\mathbf{( \% )}$ & T Ratio \\
\hline-8 & $0.17^{* *}$ & 1.12 \\
-7 & 1.09 & 1.73 \\
-6 & $1.2^{* *}$ & 1.72 \\
-5 & 0.05 & 1.03 \\
-4 & -0.3 & 0.81 \\
-3 & -0.35 & 0.81 \\
-2 & -0.64 & 0.67 \\
-1 & $-1.29^{* * *}$ & 0.3 \\
0 & $-1.21^{* * *}$ & 0.36 \\
1 & $-2.48^{* * *}$ & -0.24 \\
2 & $-3.19^{* * *}$ & -0.49 \\
3 & $-3.18^{* * *}$ & -0.48 \\
4 & $-3.83^{* * *}$ & -0.66 \\
5 & $-3.21^{* * *}$ & -0.46 \\
6 & $-3.23^{* * *}$ & -0.47 \\
7 & $-3.54^{* * *}$ & -0.55 \\
\hline
\end{tabular}

\begin{tabular}{lll}
\hline $\mathbf{t}$ & CAR [-15, t] (\%) & T Ratio \\
\hline 0 & $3.13^{* * *}$ & 2.15 \\
1 & $2.81^{* * *}$ & 2 \\
2 & $4.16^{* * *}$ & 2.34 \\
3 & $4.28^{* * *}$ & 2.27 \\
4 & $3.56^{* * *}$ & 2.07 \\
5 & $3.67^{* * *}$ & 2.07 \\
6 & $4.48^{* * *}$ & 2.37 \\
7 & $4.57^{* * *}$ & 2.32 \\
\hline
\end{tabular}

Note:***,***represent variable $10 \%, 5 \%$ and $1 \%$ level significantly; Space is limited, not noted one by one

\subsubsection{Analysis of Different Market Environmental Samples}

From the total sample, the IPO time began May 1, 2013. Shanghai Securities Composite Index, for example, from its initial 2941 points to 2170 at May 1, 2016, combined with the sample characteristics and the volatility of market period. According to the band, the market trend and high or low points will be divided into three stages. (1). May 2013 to November 2014 (shock market); (2). November 2014 to April 2015 (accelerated market); (3). April 2015 to May 2016 (rapid declined market); according to the above band classifies time period, the total sample is divided into three groups corresponding.

\begin{tabular}{lll}
\hline $\mathbf{t}$ & $\mathbf{C A R}[-\mathbf{1 5}, \mathbf{t}] \mathbf{~ ( \% )}$ & T Ratio \\
\hline-8 & 0.67 & 1.41 \\
-7 & 0.87 & 1.44 \\
-6 & $1.36^{* *}$ & 1.66 \\
-5 & 1.52 & 1.7 \\
-4 & $2.44^{* *}$ & 2.02 \\
-3 & 2.6 & 2.14 \\
-2 & $2.99^{* *}$ & 2.23 \\
-1 & $3.65^{* * *}$ & 2.39 \\
\hline
\end{tabular}

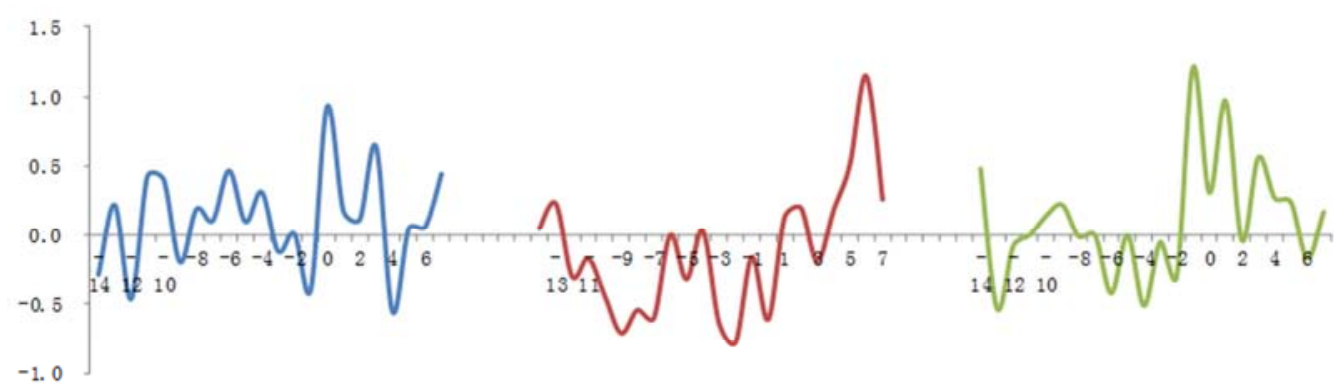

Shock Accelerated Rapid declined

Figure 2. CRA [-14, t1] of different periods mean fluctuation.

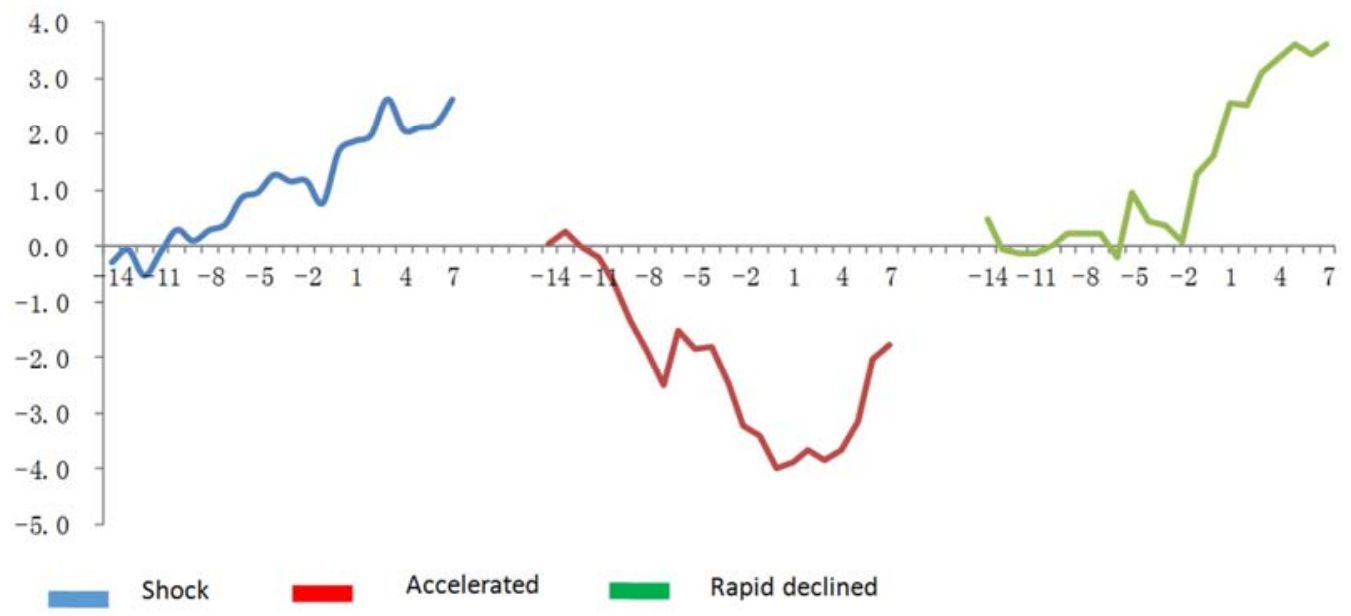

Figure 3. $A R_{i t}$ of different periods mean fluctuation. 
The first kind of market environment is slow shock market, in early May 2013 to late November 2014, for nearly 12 months, the Shanghai Securities Composite Index increased from 2170 points to 2660 points. Cumulative abnormal excess return of samples in $[-8,0]$ period is positive and reaches $1.91 \%$, indicating that the market's hot point switches is slow at the time of the fluctuation, once you start chasing the "shadow share", then it will be able to continue to obtain excess income. However, [0, 7] period reaches about $0.9 \%$, indicating that in the shock market, market speculation has tepid enthusiasm, market is still somewhat "preference" to shadow share" on the day of the IPO. The cumulative rate of return is $2.33 \%$ throughout the $[-14,7]$ period, so it suggests "shadow share" in a shock market access the market "favor."

The second kind of market, namely the market undergone more than a year after the shock rise into the accelerated phase, in early December 2014 to mid-June 2015 six months, the Shanghai Securities Composite index rose from 2667 points to 5178 points. Sample pre-IPO cumulative abnormal excess return CAR [-9,0] is significantly negative and reaches $-3.37 \%$, indicating that the bad news in a bull market that has possibility to die quickly, and hot point of market converting frequently. The publish of good news makes the already layout pioneer accelerate escape or whipsaw strongly. On the IPO and later several days that is $[0,7]$ period, "shadow share" CAR $[0,7]$ reaches $2.25 \%$. This shows that the market digests the bad effects of the IPO in advance, nd "shadow share" value has declined.

The third kind of market environment goes to the rapid decline stage. The Shanghai Composite Index in mid-June 2015 to May 3rd ten days of the year 2016 fell to 3045 points from the 5178 points. Before IPO transactions cumulative excess average earnings of sample are not significant. Unexpected that 1 day before IPO trading and 7 days later, CAR is significantly positive, CAR $[0,6]$ period was $3.52 \%$. It illustrates that the bear market lacks of hot focus, and when investors cannot buy new shares, they turned to shadow shares, so continued inflow of funds make the cumulative abnormal excess return of such stocks continued to be positive.

\section{Conclusions and Suggestions}

In this paper, we use the IPO and "shadow share" data in security market from May 2013 to May 2016 with event study method, and on the basis of IPO transactions, and use before 14 and 7 days later as window, then analyze market response of "shadow share" in different sectors and market environment, as a result, we reach the following conclusions: (1) The new listed shares on the Main Board and GEM, its" shadow share " CAR $[-8,0]$ significantly positive, and reach $3.6 \%$ and $2.96 \%$ respectively, such "shadow share" is more popular with the market, however, small board continue to like that type of "shadow share", its CAR [-14, 0] was $-2.87 \%$, CAR [0, 7] was $-2.3 \%$, showing the opposite. (2) New listed shares have different impact on "shadow share" in various market environments. In shock and rapid declined market, the market is lack of hot or hot switching is slow, so once the market began to chase the "shadow share", then continued inflow of funds make investors continue to get excess returns. On the country, in the accelerated rising market, the hot market frequently transfer, and the good news of announce has the possibility of die quickly, and it's "shadow share" CAR [-9, 0] is significantly negative, and reach $-3.37 \%$, indicating that the publish of good news makes the already layout pioneer accelerate escape or whipsaw strongly.

Based on empirical research, we suggest the following recommendations:

(1) For investors, it needs to comprehensive consider the characteristics of the plate and the market environment. If investors have not yet purchased the company's stock, they should select stock favor "shadow shares" of Main Board and GEM IPO when the market meets volatility and recession. The reason is the cumulative abnormal return of such stocks is significantly positive in the window period, so investors can outperform. If investors have been holding the stock that is down, plus the market has bullish sentiment, they must sell their "shadow share" at the first time even if at a loss, and change positions or select more value stock timely.

(2) For "shadow share", for the "shadow share" listed company itself, they need to disclose relevant information of the company and the IPO timely. Disclosing adequate and timely information of the company and new shares to the market, and avoiding abnormal volatility of stock price, this will help reduce the impact of speculation on the stock price, and manage companies to do market capitalization, and can real safeguard the interests of all shareholders.

\section{References}

[1] Guoxuan Huang, Venture capital concept stocks' price fluctuation analysis $[\mathrm{J}]$. Accounting communications venture capital, venture capital 2009 (11): 14-16.

[2] Shasha, Jiheng Wang, Venture Value and shares of listed companies price correlation analysis - based on empirical analysis of listed companies that have a venture capital concept [J]. Harbin University of Commerce (Social Science Edition). Venture 2008 (6): 94-98.

[3] weijie Wang, China small and medium enterprise board that venture capital venture institutions involved in IPO underpricing the analysis of causes [D]. Suzhou University, 2010. Venture Capital Ventures

[4] Hangde Ye, Study of impact on venture capital participation in the company's IPO the first day performance - based on the GEM IPO data [D]. Shandong University, Venture Capital 2013. Venture

[5] Min Sun, Research on market performance of VC-backed the company's IPO [D]. Zhejiang University, Venture capital 2010.

[6] Chen Wei. Research on venture capital reducing holdings' impact small board and GEM stocks liquidity [J]. Venture Financial Theory and Practice, Venture 2014 (3): 98-102. 
[7] Chemmanur T J, Loutskina E, The Role of Venture Capital Backing in Initial Public Offerings: Certification, Screening, or Market Power [J]. Ssrn Electronic Journal, 2006.

[8] Kaplan S N, Strömberg P, Financial Contracting Theory Meets the Real World: An Empirical Analysis of Venture Capital Contracts [J]. Review of Economic Studies, 2000, 70(2): págs. 281-315.
[9] Joseph L Y S, Saunders, Initial Public Offerings: The Role of Venture Capitalists [J]. Scientist, 1990, 22.

[10] Hochberg Y V, Venture Capital and Corporate Governance in the Newly Public Firm [J]. Social Science Electronic Publishing, 2010, 16(2): 429-480. 